\title{
Angiographic assessment of prospectively determined non-invasive reperfusion indices in acute myocardial infarction
}

\author{
A J Oude Ophuis, F W Bär, F Vermeer, W Janssen, P A Doevendans, R J Haest, \\ W R Dassen, H J J Wellens
}

\begin{abstract}
Objective-To investigate the value of non-invasive reperfusion indices in acute myocardial infarction, avoiding the possible need for acute coronary angiography and subsequent angioplasty. Design-In a prospective angiographic study, seven potential ECG or clinical markers of reperfusion were analysed in 230 patients with acute myocardial infarction. In all patients two 12 lead ECGs were used: the ECG on admission and the ECG immediately before coronary angiography. Non-invasive markers of reperfusion determined just before coronary angiography were prospectively correlated to thrombolysis in myocardial infarction (TIMI) flow. Data analysis correlated these non-invasive indices with coronary flow (analysis A: TIMI 2-3 $v$ TIMI 0-1 flow; analysis B: TIMI $3 v$ TIMI 0-2 flow).

Results-A sudden decrease in chest pain was the most common sign of reperfusion (36\%), followed by reduction in ST segment elevation by $\geqslant 50 \%(30 \%)$, and the development of a terminal negative T wave (20\%) in the lead with the highest ST segment elevation. Reduction in ST segment elevation by $\geqslant 50 \%$ and the appearance of an accelerated idioventricular rhythm (AIVR) had the highest positive predictive value for reperfusion. For analyses A and B, the positive predictive values were $85 \%$ and $66 \%$ for resolution of ST segment elevation, and $94 \%$ and $59 \%$ for AIVR, respectively. The presence of three or more non-invasive markers of reperfusion predicted TIMI 3 flow accurately in $80 \%$ of cases.

Conclusions-The prospective use of non-invasive indices of reperfusion is simple, practical, and can be of value in assessing coronary patency in patients admitted with acute myocardial infarction. Using these indices, discrimination between TIMI $0-1$ and TIMI 2-3 flow can be made with good accuracy. However, TIMI 3 flow cannot be determined reliably. The use of such noninvasive indices depends on the goal of reperfusion.

(Heart 2000;84:164-170)
\end{abstract}

Keywords: reperfusion indices; acute myocardial infarction

Several studies have shown the value of non-invasive reperfusion indices in acute myocardial infarction. ${ }^{1-4}$ Various non-invasive indices were found useful for determining coronary reperfusion, such as resolution of ST segment elevation, reduction in chest pain, and the appearance of certain arrhythmias. Most of these studies were done in small numbers of patients, and the interval between the noninvasive evaluation and the angiographic validation of reperfusion was variable. Many of the studies were retrospective. The prospective value of non-invasive indices of reperfusion is still unclear.

Determination of the presence of coronary reperfusion through simple non-invasive tools is of obvious value in establishing successful thrombolysis and identifying spontaneous reperfusion in patients referred for percutaneous transluminal coronary angioplasty (PTCA). Acute intervention in the presence of reperfusion has not been shown to improve clinical outcome, and coronary angiography should be withheld in cases where non-invasive markers of reperfusion are of sufficient predictive value. ${ }^{56}$ When coronary blood flow has not been restored, emergency PTCA is likely to be helpful. ${ }^{7-10}$ The value of intracoronary intervention in patients with thrombolysis in myocardial infarction (TIMI) 2 flow is still a matter of debate. Anderson et al showed a better prognosis in patients with TIMI 3 flow than in those with TIMI 2 flow. ${ }^{11}$ Other investigators could not confirm these results. ${ }^{12}{ }^{13}$ If the findings of Anderson et al were correct, it could be important to discriminate non-invasively between patients with TIMI $0-2$ and those with TIMI 3 flow in the infarct related artery; otherwise, it is only necessary to differentiate between TIMI 0-1 and TIMI 2-3 flow.

Our aim in this angiographically controlled study was to determine the prospective value of seven reperfusion indices. If non-invasive reperfusion indices can reliably predict adequate restoration of flow, the costly, possibly hazardous, and often logistically difficult procedure of acute coronary angiography can be avoided.

\section{Methods}

STUDY PATIENTS

Two hundred and thirty consecutive patients with acute coronary angiography were enrolled in the study. All patients were admitted within the first six hours after acute myocardial infarction. Entry in the study required chest pain for at least 30 minutes not responding to glyceryl trinitrate, associated with more than $0.1 \mathrm{mV}(1 \mathrm{~mm}) \mathrm{ST}$ segment elevation in two or 
A

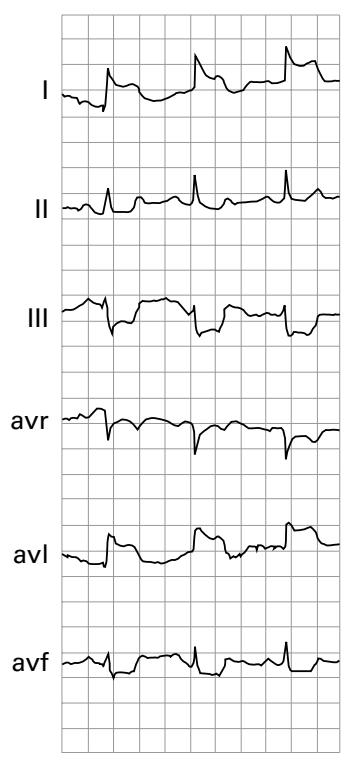

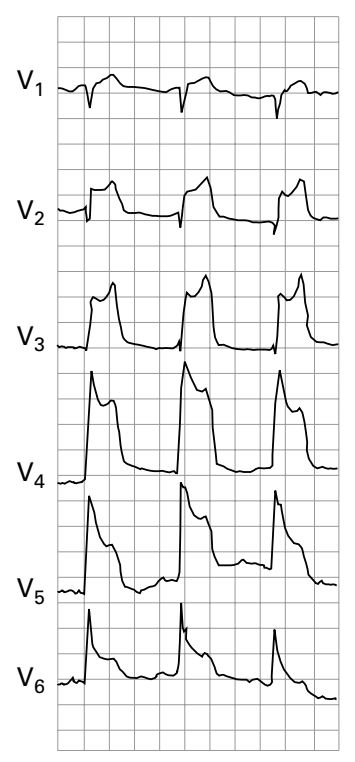

B

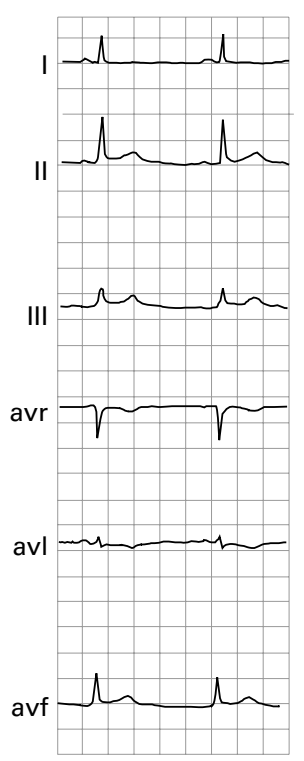

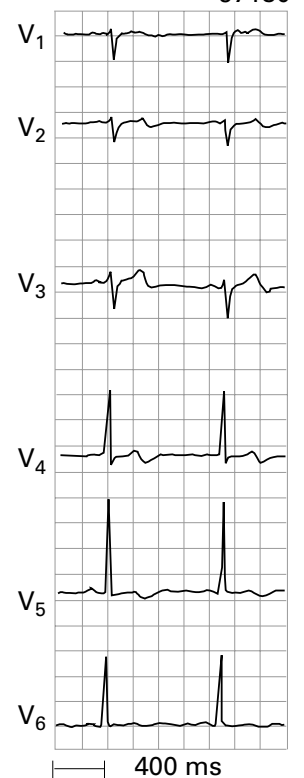

Figure 1 Example of the resolution of ST segment elevation and development of terminal negative $T$ waves as a sign of reperfusion. Patient with extensive anterior wall myocardial infarction treated with a thrombolytic agent. (A) Admission ECG showing ST segment elevation in anterior leads (most prominent in lead V4). (B) ECG just before the first intracoronary contrast injection showing TIMI 3 flow. Resolution of ST segment elevation $\geqslant 50 \%$ and development of terminal negative $T$ wave in lead V4. This patient also had a sudden decrease in chest pain.

more limb leads and at least $0.2 \mathrm{mV}$ in two or more contiguous precordial leads, according to normal standards for thrombolytic treatment. Thrombolytic treatment (streptokinase, saruplase, alteplase) was given in hospital, usually in the emergency department. The reasons for acute coronary angiography were: primary PTCA, coronary angiography after thrombolytic treatment in the setting of a study protocol, and possible rescue PTCA.

HISTORY

Careful attention was paid to the evolution of chest pain. Before coronary angiography, each patient was asked to rate the severity of chest pain to indicate whether sudden changes had occurred. Chest pain was then classified as unchanged, suddenly decreased, or suddenly increased between admission and the start of coronary angiography.

Table 1 Definitions of the indices of reperfusion

\begin{tabular}{|c|c|}
\hline ST segment resolution $\geqslant 50 \%$ & $\begin{array}{l}\text { Reduction of } \geqslant 50 \% \text { in ST segment elevation in the } \\
\text { infarct lead showing the highest ST segment } \\
\text { elevation measured from the J point, between } \\
\text { admission ECG and ECG just before CAG }\end{array}$ \\
\hline Sudden decrease in chest pain & $\begin{array}{l}\text { Sudden decrease in chest discomfort in the period } \\
\text { between admission ECG and CAG, as indicated by } \\
\text { the patient }\end{array}$ \\
\hline Sudden increase in chest pain & $\begin{array}{l}\text { Sudden increase in chest discomfort in the period } \\
\text { between admission ECG and CAG, as indicated by } \\
\text { the patient }\end{array}$ \\
\hline Accelerated idioventricular rhythm & $\begin{array}{l}\text { Run of }>4 \text { consecutive non-premature ventricular } \\
\text { complexes at a rate between } 80 \text { and } 125 \text { beats/min } \\
\text { present on the ECG in the period between } \\
\text { admission ECG and CAG }\end{array}$ \\
\hline Ventricular fibrillation & $\begin{array}{l}\text { Episode of ventricular fibrillation requiring } \\
\text { defibrillation between admission ECG and CAG }\end{array}$ \\
\hline Ventricular ectopy & $\begin{array}{l}\text { Premature ventricular complexes present on } \\
\text { admission ECG or ECG just before CAG }\end{array}$ \\
\hline Terminal negative $\mathrm{T}$ wave & $\begin{array}{l}\text { The development of terminal negative T wave } \geqslant 0.1 \\
\mathrm{mV}(\geqslant 1 \mathrm{~mm}) \text { in the infarct lead with highest } \mathrm{ST} \\
\text { segment elevation on the ECG just before CAG }\end{array}$ \\
\hline
\end{tabular}

CAG, coronary angiography.
ELECTROCARDIOGRAPHY

A 12 lead ECG recording was made on admission and just before coronary angiography (fig 1). These two records were compared and used to assess the presence of ECG reperfusion indices. The criteria for reperfusion, as listed in table 1 , were checked by the angiographer just before the angiographic procedure and documented in the patient's record form. Using these criteria, the angiographer additionally predicted the presence or absence of patency of the infarct related artery before the start of coronary angiography.

\section{CORONARY ANGIOGRAPHY}

All patients underwent coronary angiography in the acute phase of the acute myocardial infarction, usually within a median of 73 minutes after admission to the Academic Hospital of Maastricht (table 2). Coronary angiography was performed using the Seldinger technique. The first intracoronary injection was used to determine coronary flow. Reperfusion of the infarct related artery was determined according to the TIMI criteria. ${ }^{6}$ In cases of inferoposterior infarction combined with multivessel disease, the right precordial leads and coronary angiographic appearances were used to determine whether the circumflex artery or the right coronary artery was the infarct related artery. ${ }^{14}$

\section{STATISTICAL ANALYSIS}

The data were stored in a computer and analysed by SPSS/7.0. Data were expressed as mean (SD) for continuous variables or as rates for categorical variables. For categorical variables, the $\chi^{2}$ test, or when 
Table 2 Characteristics of the 230 patients

\begin{tabular}{|c|c|c|}
\hline & $n$ & $\%$ \\
\hline Age (years) (mean (SD)) & \multicolumn{2}{|c|}{$59(11)$} \\
\hline Male & 176 & 77 \\
\hline Previous infarction & 29 & 13 \\
\hline Patients with anterior infarction & 119 & 52 \\
\hline Thrombolytic treatment & 165 & 72 \\
\hline Referred for primary PTCA & 65 & 28 \\
\hline $\begin{array}{l}\text { Hospital admission to CAG (min) } \\
\text { median }^{\star}\end{array}$ & 73 & $34 ; 102$ \\
\hline Maximum AST (U/l) median ${ }^{\star}$ & 241 & $132 ; 340$ \\
\hline
\end{tabular}

${ }^{\star}$ Range ( 25 th centile; 75 th centile).

AST, aspartate aminotransferase; CAG, coronary angiography;

PTCA, percutaneous transluminal coronary angioplasty.

Table 3 Angiographic data on the 230 patients

\begin{tabular}{|c|c|c|c|c|}
\hline & \multirow[b]{2}{*}{$n$} & \multirow[b]{2}{*}{$\%$} & \multicolumn{2}{|c|}{ One year mortality* } \\
\hline & & & $n$ & $\%$ \\
\hline All patients & 230 & 100 & 15 & 6.5 \\
\hline \multicolumn{5}{|c|}{ Infarct related artery } \\
\hline LAD & 119 & 51.7 & 9 & 7.5 \\
\hline $\mathrm{CX}$ & 14 & 6.1 & 0 & 0 \\
\hline RCA & 96 & 41.8 & 6 & 6.2 \\
\hline Graft & 1 & 0.4 & 0 & 0 \\
\hline \multicolumn{5}{|c|}{ TIMI flow first injection } \\
\hline TIMI 0 & 106 & 46.1 & 8 & 7.5 \\
\hline TIMI 1 & 25 & 10.9 & 3 & 12 \\
\hline TIMI 2 & 32 & 13.9 & 2 & 6.2 \\
\hline TIMI 3 & 67 & 29.1 & 2 & 3.0 \\
\hline \multicolumn{5}{|c|}{ Vessel disease } \\
\hline One & 134 & 58.3 & 8 & 5.9 \\
\hline Two & 45 & 19.5 & 1 & 2.2 \\
\hline Three & 51 & 22.2 & 6 & 11.7 \\
\hline PTCA & 143 & 62.2 & 8 & 5.5 \\
\hline
\end{tabular}

^Three patients were lost to follow up.

applicable Fisher's exact test, was used. A probability $(p)$ value $<0.05$ was considered statistically significant.

\section{Results}

The characteristics of the 230 patients are listed in table 2 . One hundred and sixty five patients $(72 \%)$ had received thrombolytic treatment. Coronary angiography data are shown in table 3. Fifty seven per cent of the patients had TIMI 0 or 1 , and $29 \%$ had TIMI 3 coronary flow at the first intracoronary injection. One year mortality was lowest in the patients with TIMI 3 flow at first injection (table 3). The frequency of the individual non-invasive reperfusion indices is shown in table 4 . The frequencies of noninvasive indices of reperfusion were not significantly different between the patients with or without thrombolytic treatment (table 4).

A sudden decrease in chest pain was the most common feature of reperfusion (36\%), followed by resolution of ST segment elevation $(30 \%)$. The average degree of ST segment elevation in the most prominent infarct lead on the admission ECG was 4.7 (3.4) $\mathrm{mm}$ (range $1-23 \mathrm{~mm}$ ). Just before coronary angiography, mean ST segment elevation in the same lead was 4.1 (3.6) $\mathrm{mm}$ (range $0-30 \mathrm{~mm}$ ). Thirteen patients $(6 \%)$ had a sudden increase of chest pain after admission but before coronary angiography. The non-invasive reperfusion indices were correlated with the TIMI flow at the first angiographic view of the infarct related artery as follows: analysis A, TIMI 2-3 $v$ TIMI 0-1 flow (table 5); analysis B, TIMI 3 v TIMI 0-2 flow (table 6). Except for the sudden increase in chest pain and ventricular fibrillation, all indices correlated well with TIMI flow. Table 7 shows the specificity, sensitivity, and positive and negative predictive value of the number of reperfusion indices required in order to determine TIMI $2-3$ or TIMI 3 flow in the infarct related artery. The presence of more than three indices of reperfusion is highly specific for the presence of TIMI 3 flow in the infarct related artery (99\%).

Table 4 Frequency of non-invasive indices of reperfusion in the 230 patients

\begin{tabular}{|c|c|c|c|c|c|c|c|}
\hline & \multicolumn{2}{|c|}{$\begin{array}{l}\text { All } \\
(n=230)\end{array}$} & \multicolumn{2}{|c|}{$\begin{array}{l}\text { Thrombolysis } \\
(n=165)\end{array}$} & \multicolumn{2}{|c|}{$\begin{array}{l}\text { No thrombolysis } \\
(n=65)\end{array}$} & \multirow[b]{2}{*}{$p$ Value } \\
\hline & $n$ & $\%$ & $n$ & $\%$ & $n$ & $\%$ & \\
\hline \multicolumn{8}{|l|}{ Chest pain } \\
\hline Sudden decrease & 83 & 36 & 65 & 39 & 18 & 28 & 0.070 \\
\hline Sudden increase & 13 & 6 & 7 & 4 & 6 & 9 & 0.257 \\
\hline Resolution ST segment elevation $\geqslant 50 \%$ & 68 & 30 & 51 & 31 & 17 & 26 & 0.657 \\
\hline AIVR & 17 & 7 & 15 & 9 & 2 & 3 & 0.194 \\
\hline Ventricular fibrillation & 13 & 6 & 10 & 6 & 3 & 5 & 0.904 \\
\hline Ventricular ectopy & 33 & 14 & 23 & 14 & 10 & 15 & 0.956 \\
\hline Development of terminal negative $T$ wave & 46 & 20 & 34 & 21 & 12 & 18 & 0.880 \\
\hline
\end{tabular}

AIVR, accelerated idioventricular rhythm.

Table 5 Correlation of non-invasive reperfusion indices with TIMI 2-3 flow in the 230 patients

\begin{tabular}{|c|c|c|c|c|c|c|c|}
\hline & \multicolumn{2}{|c|}{ TIMI 0-1 } & \multicolumn{2}{|c|}{ TIMI 2-3 } & \multirow{2}{*}{$\begin{array}{l}P P V \\
(\%)\end{array}$} & \multirow{2}{*}{$\begin{array}{l}N P V \\
(\%)\end{array}$} & \multirow[b]{2}{*}{$p$ Value } \\
\hline & $n$ & $\%$ & $n$ & $\%$ & & & \\
\hline All patients & 131 & 100 & 99 & 100 & & & \\
\hline ST segment resolution $\geqslant 50 \%$ & 10 & 7.6 & 58 & 58.6 & 85 & 75 & 0.001 \\
\hline Sudden decrease in chest pain & 8 & 6.1 & 65 & 65.7 & 89 & 78 & 0.001 \\
\hline Sudden increase in chest pain & 7 & 5.3 & 6 & 6.1 & 46 & 57 & 0.83 \\
\hline AIVR & 1 & 0.8 & 16 & 16.2 & 94 & 61 & 0.001 \\
\hline Ventricular fibrillation & 5 & 3.8 & 8 & 8.1 & 62 & 58 & 0.17 \\
\hline Ventricular ectopy & 9 & 6.9 & 24 & 24.2 & 73 & 62 & 0.001 \\
\hline Negative $T$ wave & 11 & 8.4 & 35 & 35.4 & 76 & 65 & 0.001 \\
\hline
\end{tabular}

AIVR, accelerated idioventricular rhythm; NPV, negative predictive value; PPV, positive predictive value. 
Table 6 Correlation of non-invasive reperfusion indices with TIMI 3 flow in the 230 patients

\begin{tabular}{|c|c|c|c|c|c|c|c|}
\hline & \multicolumn{2}{|c|}{ TIMI 0-2 } & \multicolumn{2}{|c|}{ TIMI 3} & \multirow{2}{*}{$\begin{array}{l}P P V \\
(\%)\end{array}$} & \multirow{2}{*}{$\begin{array}{l}N P V \\
(\%)\end{array}$} & \multirow[b]{2}{*}{$p$ Value } \\
\hline & $n$ & $\%$ & $n$ & $\%$ & & & \\
\hline All patients & 163 & 100 & 67 & 100 & & & \\
\hline ST segment resolution $\geqslant 50 \%$ & 23 & 14.1 & 45 & 67.2 & 66 & 86 & 0.001 \\
\hline Sudden decrease in chest pain & 36 & 22.1 & 47 & 70.1 & 57 & 86 & 0.001 \\
\hline Sudden increase in chest pain & 9 & 5.5 & 4 & 6.0 & 31 & 71 & 0.92 \\
\hline AIVR & 7 & 4.3 & 10 & 14.9 & 59 & 73 & 0.005 \\
\hline Ventricular fibrillation & 7 & 4.3 & 6 & 9.0 & 46 & 72 & 0.17 \\
\hline Ventricular ectopy & 18 & 11.0 & 15 & 22.4 & 45 & 74 & 0.03 \\
\hline Negative $T$ wave & 18 & 11.7 & 28 & 41.8 & 61 & 79 & 0.001 \\
\hline
\end{tabular}

Before starting the procedure the cardiologist predicted the reperfusion. TIMI 2-3 flow in the infarct related artery was accurately predicted in $88 \%$ of cases. However, TIMI 3 coronary flow prediction could only be made in $67 \%$. Where improved flow could be predicted by the cardiologist performing the angiography, the clinical outcome (one year mortality) appeared to be excellent $(0 \%)$.

\section{Discussion \\ The treatment of acute myocardial infarction is directed towards limitation of infarct size, in the hope of reducing complications and prolonging life. ${ }^{15} 16$ Patients treated promptly after the onset of symptoms by restoration of patency in the infarct related artery will be expected to have the greatest benefit. Patients with complete reperfusion of the infarct related artery will have a better prognosis than those with no reperfusion or only incomplete restora- tion of flow. ${ }^{11}$ The one year mortality is $5 \%$ in patients with TIMI 3, compared with $27 \%$ in patients with TIMI 0/1 flow. ${ }^{17}$ It would therefore be of considerable value to be able to detect adequate reperfusion non-invasively. In cases where non-invasive reperfusion indices suggest insufficient coronary flow, acute coron- ary angiography followed by PTCA, if indi- cated, may improve prognosis.}

\section{STUDY POPULATION}

The reasons for performing acute coronary angiography in this group of 230 patients varied, as described in Methods, and $72 \%$ had received thrombolytic treatment. TIMI 0-1 flow was present in $57 \%$ (table 3 ), which is rather a high proportion. This is in part explained by the contribution of patients referred for primary PTCA.

Table 7 The value of the total number of non-invasive indices of reperfusion present for predicting either TIMI 2-3 or TIMI 3 flow of the infarct related artery

\begin{tabular}{llccc}
\hline No of indices & Sensitivity (\%) & Specificity (\%) & PPV (\%) & NPV (\%) \\
\hline TIMI 2-3 & & & & \\
$>0$ & 85 & 71 & 69 & 86 \\
$>1$ & 72 & 87 & 81 & 80 \\
$>2$ & 46 & 95 & 88 & 70 \\
$>3$ & 10 & 100 & 100 & 60 \\
TIMI 3 & & & & \\
$>0$ & 78 & 78 & 58 & 93 \\
$>1$ & 54 & 90 & 69 & 89 \\
$>2$ & 12 & 99 & 80 & 73 \\
$>3$ & & & & 78 \\
\hline
\end{tabular}

$\mathrm{NPV}$, negative predictive value; PPV, positive predictive value; TIMI, thrombolysis in myocardial infarction.
TIMI FLOW

Coronary angiography has remained the gold standard for determining the patency of the infarct related artery ever since DeWood et al demonstrated the safety and feasibility of acute coronary angiography in acute myocardial infarction. ${ }^{19}$ However, this diagnostic procedure has disadvantages. Logistic problems may arise if it has to be done in every patient with an acute infarct. Apart from the cost, acute coronary angiography may have adverse effects such as bleeding at the puncture site, especially after the administration of thrombolytic agents. Thus, effective non-invasive detection of reperfusion will diminish the need for acute coronary angiography, especially after thrombolytic treatment. Our present prospective study documents the value of seven noninvasive indices of reperfusion as predictors of coronary reperfusion, enabling differentiation between TIMI $0-1$ and TIMI 2-3 flow in the infarct related artery. The obvious advantages of the use of these non-invasive indices of reperfusion are that they are simple, cheap, and patient friendly.

WHAT IS THE GOAL OF REPERFUSION: TIMI 2 FLOW OR TIMI 3 FLOW?

As stated earlier, discussion over whether to aim at TIMI 2 flow or TIMI 3 flow in the infarct related artery is still ongoing, though the achievement of TIMI 3 flow is favoured. Noninvasive discrimination between TIMI $0-2$ flow and TIMI 3 flow is important if the outcome of patients with TIMI 3 flow is considered superior to that with TIMI 2 flow. If on the other hand it is assumed that there is little difference between TIMI 2 flow and TIMI 3 flow with respect to clinical outcome, then it is more important to discriminate between TIMI $0-1$ and TIMI 2-3 flow. Limitations in budget, manpower, access to coronary angioplasty, and the distance of travel to an angioplasty facility may make optimal management impossible, and treatment goals will ultimately depend on local and personal circumstances.

The issue of TIMI 3 flow or TIMI 2-3 flow may in fact be important in community hospitals without PTCA facilities, which consider the transfer of patients with acute myocardial infarction for emergency PTCA. This scenario is common in many European countries where angioplasty facilities are limited and the distance to tertiary PTCA centres is considerable. We recently published a study showing that early referral for intentional rescue angioplasty can be beneficial. In that study it was 
shown that patients with non-invasive signs of reperfusion in whom acute coronary angiography was not done had a very good prognosis. $^{20}$

INCIDENCE AND VALUE OF THE DIFFERENT NON-INVASIVE INDICES

Reduction in ST segment elevation by $\geqslant 50 \%$ occurred in $30 \%$ of the patients in this study population, with a good positive and negative predictive value in identifying patients with reperfusion. In $85 \%$ of the patients, TIMI $2-3$ flow was correctly predicted. However, the positive predictive value of this non-invasive reperfusion index fell to $66 \%$ when it was used to predict TIMI 3 flow. Thus using this non-invasive index only would lead to $15 \%$ of patients being falsely identified as having TIMI $2-3$ flow, and $34 \%$ of patients falsely identified as having TIMI 3 flow.

The weak prediction of complete restoration of flow (TIMI 3 flow) raises questions about the value of this single reperfusion index. It is clear that there is considerable overlap in ST segment behaviour in patients with TIMI 2 or TIMI 3 flow in the infarct related artery. Our findings are comparable with those of Kircher et al, who found qualitative ST segment improvement in $33 \%$ of patients with acute myocardial infarction, associated with an $88 \%$ probability of reperfusion. ${ }^{21}$ Clemmensen et al showed that a decrease of $20 \%$ in the sum of ST segment elevations was a useful noninvasive predictor of TIMI 2-3 flow in the infarct related artery (positive predictive value $88 \%$; negative predictive value $80 \%){ }^{22}$ In a small test population, Hogg and coworkers, using the lead with maximum ST segment deviation on the standard 12 lead ECG, found that a $50 \%$ reduction in ST elevation was $67 \%$ specific and $93 \%$ sensitive; however, perfusion criteria were not given. ${ }^{23}$ Many other studies have been reported, using a different percentage of ST segment resolution, usually in small patient groups and with a wide variation in the time between the ECG recording and the determination of the state of reperfusion. The strength of our study lies in its prospective nature, in the simplicity of using only the ECG lead with the highest ST segment elevation, the immediate coronary angiography after the second ECG, giving the correct perfusion status, and the rather large patient population with a $43 \%$ coronary artery patency.

SUDDEN CHANGE IN CHEST PAIN

Increase in or relief of chest pain is a subjective finding during acute myocardial infarction, and is dependent on the state of ischaemia and the time of evaluation. Kircher et al showed the relation between sudden resolution of chest pain and coronary artery patency. ${ }^{21}$ However, extensive and prolonged myonecrosis can be accompanied by a gradual decrease in symptoms (the natural course of myocardial infarction). The duration between the onset of pain and assessment of severity of complaints was rather short in our study (less than 7.5 hours). During this time interval, symptoms are usually still present. Pain relieving drugs and the administration of anti-ischaemic agents can contribute to a decrease in symptoms and may have influenced the assessment of chest pain. ${ }^{24}$ Also, cyclic changes in coronary perfusion and coronary tone can contribute to changes in chest pain. Finally, an increase in chest pain may be experienced just after reperfusion of the infarct related artery and could be caused by washout of toxic metabolites. As in other studies, the predictive value of a sudden decrease or increase in chest pain had only a limited predictive value. ${ }^{36}$

ARRHYTHMOGENICITY OF REPERFUSION

Owing to the washout phenomenon during reperfusion of the infarct related artery, a sudden change in electrolytes, free radicals, fatty acids, and other factors can result in electrical instability and tissue heterogeneity of the reperfused myocardium. These are considered to be the ideal conditions for the occurrence of arrhythmias such as accelerated idioventricular rhythm (AIVR), increased ventricular ectopy, and ventricular fibrillation. ${ }^{27}$ Gressin et al have previously shown that AIVR and other ventricular arrhythmias can be observed in patients with an occluded artery more than five hours after the onset of acute myocardial infarction. ${ }^{28}$ These ventricular rhythm disturbances will be observed during the first hour after reperfusion and this fits well within our timing of coronary angiography. As shown in table 4 , AIVR has a high positive predictive value $(94 \%)$ in discriminating between TIMI $0-1$ and TIMI 2-3 flow in the infarct related artery, but the incidence of AIVR is low. Its positive predictive value falls to $59 \%$ if TIMI 3 flow has to be discriminated from TIMI 0-2 flow. It seems likely that the arrhythmias are the result of reperfusion of the infarct related artery and not because of the intensity of flow. We made similar observations with respect to ventricular fibrillation and the occurrence of ventricular ectopy in the present study.

DEVELOPMENT OF TERMINAL NEGATIVE T WAVE Myocardial ischaemia is a clinical condition associated with primary $T$ wave changes. ${ }^{329}$ In the present study the early occurrence of a terminal negative $\mathrm{T}$ wave of more than $0.1 \mathrm{mV}$ (1 $\mathrm{mm}$ ) in the most abnormal infarct lead was shown to be a sign of coronary reperfusion $(\mathrm{p}<0.001)$. Although the positive predictive value of this index in determining TIMI 2-3 flow was reasonably good, it became poor if used for the prediction of TIMI 3 flow. It must be stated that for this index, as for the other indices used, there was considerable overlap in presentation.

PROSPECTIVE PREDICTION OF REPERFUSION Before the start of the procedure, the cardiologist performing the angiography was asked to record his prediction about reperfusion. As previously stated, this cardiologist was free to use the reperfusion indices at his own discretion. He was able to predict reperfusion defined by TIMI 2-3 flow correctly in $88 \%$ of the 
patients and reperfusion defined as TIMI 3 flow in $66 \%$. Prediction of complete restoration of flow by the cardiologist correlated with excellent clinical outcome with respect to one year mortality.

\section{STUDY LIMITATIONS}

The conclusions that can be derived from this study have to be drawn in the light of the rather heterogeneous group of patients referred for coronary angiography, because of research protocols, possible rescue PTCA, or primary PTCA. Because patients were also referred for primary PTCA, the overall patency rate at the first intracoronary injection was only $43 \%$. We believe, however, that the patients used in the study population reflect every day cardiological practice. The use of only the infarct lead with highest ST segment elevation to determine $\geqslant 50 \%$ resolution and the development of $\mathrm{T}$ wave negativity was chosen to increase the simplicity of the procedure. The fact that only two ECG recordings were used does not take into account the fact that ST segment elevation often fluctuates in the setting of acute myocardial infarction. However, the decision to perform acute coronary angiography has to be made promptly and cannot await repeated ECG analyses.

The evaluation of chest pain is a subjective measure, but in our experience sudden changes in chest pain are well recognised by patients. Complete avoidance of antiischaemic agents might allow a more accurate determination of reperfusion with respect to chest pain; however, it does not seem ethical not to give medication that could limit infarct size.

\section{CONCLUSIONS}

Using acute coronary angiography as the gold standard for the perfusion grade of the infarct related artery in 230 patients with acute myocardial infarction, we confirmed that noninvasive indices (especially the ST segment) are of value in discriminating between TIMI 0-1 and TIMI 2-3 flow in the infarct related artery. The inability of non-invasive indices of reperfusion to differentiate between patients with TIMI 3 flow and TIMI 2 flow with great accuracy is a limitation, because TIMI 3 flow may be associated with a better prognosis than TIMI 2 flow. Where it is believed that TIMI 2 flow has a poor prognosis, acute coronary angiography should be recommended to facilitate further treatment. This will depend on the belief that only TIMI 3 flow should be accepted and also on the local circumstances. In European countries where access to angioplasty facilities is limited and manpower and health care budgets restricted, choices with respect to the optimal goal of treatment will have to be made. From the present data it is clear that an entirely accurate non-invasive confirmation of the re-establishment of coronary artery blood flow, within therapeutically acceptable time limits, is not available at present.
Presented in part at the scientific sessions of the American College of Cardiology, Atlanta, Georgia, USA, $1998(\mathfrak{F}$ Am Coll lege of Cardiology, Atlant 1998;31:200A).

1 Krucoff MW, Croll MA, Pope JE, et al. Continuously updated 12-lead ST segment recovery analysis for myocardial infarct artery patency assessment and its correlation with multiple simultaneous early angiographic observawith multiple simultaneous early ang
tions. Am f Cardiol 1993;71:145-51.

2 Klootwijk P, Langer A, Meij S, et al. Non-invasive prediction of reperfusion and coronary artery patency by continuous ST segment monitoring in the GUSTO-1 trial. Eur Heart 7 1996;17:689-98.

3 Doevendans PA, Gorgels AP, Van der Zee R, et al. Electrocardiographic diagnosis of reperfusion during thrombolytic therapy in acute myocardial infarction. Am $\mathcal{f}$ Cardiol 1995; $75: 1206-10$

4 Califf RM, O'Neill W, Stack RS, et al. Failure of simple clinical measurements to predict reperfusion status after intravenous thrombolysis. Ann Intern Med 1988;108: intraven $658-62$.

5 Simoons ML, Arnold AER, Betriu A, et al, for the European Cooperative Study Group for recombinant tissue-type plasminogen activator (rTPA). Thrombolysis with tissue plasminogen activator (rTPA). Thrombolysis with tissue plasminogen activator in acute myocardial infarction: no angioplasty. Lancet 1988;i:197-203.

6 TIMI research group. Immediate $v s$ delayed catheterization TIMI research group. Immediate $v s$ delayed catheterization
and angioplasty following thrombolytic therapy for acute myocardial infarction. TIMI $2 \mathrm{~A}$ results. $\mathscr{F A M A}$ 1988;260: 2849-58.

7 Ellis SG, Da Silva ER, Heyndrickx G, et al. Randomized comparison of rescue angioplasty with conservative management of patients with early failure of thrombolysis for acute myocardial infarction. Circulation 1994;90:2280-4.

8 Zijlstra F, de Boer MJ, Hoorntje JCA, et al. A comparison of immediate coronary angioplasty with intravenous streptokinase in acute myocardial infarction. $N$ Engl $7 \mathrm{Med}$ 1993;328:680-4.

9 Grines CL, Browne KF, Marco J, et al. for the primary angioplasty in myocardial infarction study group: a comparison of immediate angioplasty with thrombolytic therapy for acute myocardial infarction. $N$ Engl $\mathcal{F}$ Med 1993;328:680-4.

10 Gibbons RJ, Holmes DR, Reeder GS, et al. Immediate angioplasty compared with the administration of a thrombolytic agent followed by conservative treatment for myocardial infarction. N Engl f Med 1993;328:685-91

11 Anderson JL, Karagounis LA, Becker LC, et al. TIMI perfusion grade 3 but not grade 2 results in improved outcome after thrombolysis for myocardial infarction. Ventriculographic, enzymatic and electrocardiographic evi-
dence of the TEAM-3 study. Circulation 1993;87:1829-39.

12 Bär FW, Meyer J, Vermeer F, et al. Comparison of saruplase and alteplase in acute myocardial infarction. Am $\mathcal{F}$ Cardiol 1997;79:727-32.

13 Bär FW, Meyer J, Boland J, et al. Bolus administration of saruplase in Europe (Base): a pilot study in patients with acute myocardial infarction. F Thrombosis Thrombolysis 1998; 6:147-53.

14 Braat S, Gorgels A, Bär F, et al. Value of the ST-T segment in lead $\mathrm{V}_{4} \mathrm{R}$ in inferior wall acute myocardial infarction to predict the site of coronary arterial occlusion. Am $\mathrm{f}$ Cardiol predict the site of

15 Raitt MH, Maynard C, Wagner GS, et al. Relation between symptom duration before thrombolytic therapy and final infarct size. Circulation 1996;93:48-53

16 Mauri F, Maggioni AP, Franzosi MG, et al. A simple electrocardiographic predictor of the outcome of patients with acute myocardial infarction treated with a thrombolytic agent. $\mathcal{F}$ Am Coll Cardiol 1994;24:600-7.

17 Kennedy JW, Ritchie JL, Davis KB, et al. Western Washington randomized trial of intracoronary streptokinase in acute myocardial infarction. N Engl f Med 1983;309: 1477-82.

18 Moreno FL, Karagounis L, Marshall H, et al. Thrombolysis-related early patency reduces ECG late potentials after acute myocardial infarction. Am Heart $\mathcal{f}$ 1992;124:557-64.

19 DeWood MA, Spores J, Notske R, et al. Prevalence of total coronary occlusion during the early hours of transmural coronary occlusion during the early hours of transmural
myocardial infarction. N Engl f Med 1980;303:897-902.

20 Oude Ophuis AJ, Bär FW, Vermeer F, et al. Early referral for intentional rescue PTCA after initiation of thrombolytic therapy in patients admitted to a community hospital therapy in patients admitted to a community hospital because of a large
$1999 ; 137: 846-54$.

21 Kircher BJ, Topol EJ, O'Neill WW, et al. Prediction of infarct coronary artery recanalization after intravenous thrombolytic therapy. Am f Cardiol 1987;59:513-15.

22 Clemmensen P, Ohman ME, Sevilla DC, et al. Changes in standard electrocardiographic ST segment elevation predictive of successful reperfusion in acute myocardial infarction. Am f Cardiol 1990;66:1407-11.

23 Hogg KJ, Hornung RS, Howie CA, et al. Electrocardiographic prediction of coronary artery patency after thrombolytic treatment in acute myocardial infarction: use of the ST segment as a non-invasive marker. Br Heart $\mathcal{f}$ 1988:60:275-80

24 Gold HK, Leinbach RC, Harper RW. Usefulness of intravenous propanolol in predicting left anterior descending blood flow during anterior myocardial infarction. $A m \mathcal{F}$ Cardiol 1984;54:264-58. 
25 Herlitz J, Richter A, Hjalmarson A, et al. Variability of chest pain in suspected acute myocardial infarction according to subjective assessment and require

26 Shah PK, Cercek B, Lew AS, et al. Angiographic validation of bedside markers of reperfusion. 7 Am Coll Cardiol 1993;21:55-61

27 Gorgels AP, Vos MA, Letsch IS, et al. Usefulness of the accelerated idioventricular rhythm as a marker for myocardia necrosis and reperfusion during thrombolytic therapy in acute myocardial infarction. Am $\mathcal{F}$ Cardiol 1988;61:231-5.
28 Gressin V, Louvard Y, Pezzano M, et al. Holter recording of ventricular arrhythmias during intravenous thrombolysis for acute myocardial infarction. $A m$ f Cardiol;1992:69: $152-9$.

29 De Zwaan C, Bär FW, Janssen JHA, et al. Angiographic and clinical characteristics of patients with unstable angina howing an ECG pattern indicating critical narrowing of the proximal ILAD coronary artery. Am Heart $\mathcal{F} 1989 ; 117$ : 657-65.

\section{Enlargement of cardiac rhabdomyoma and myocardial ischaemia during corticotropin treatment for infantile spasm}

Multiple large cardiac tumours were detected by fetal echocardiography (panel A); tuberous sclerosis was also diagnosed. During the first 3 months of the infant girl's life these tumours in the left and right ventricles decreased to less than half their circumference at birth (panel B). However, the patient developed infantile spasms at the age of 4 months and corticotropin treatment was initiated (once a day for two weeks, tapering off over three months). At 6 month of age a heart murmur was detected in the patient. Echocardiography showed pronounced enlargement of the tumours in both ventricles and a small tumour extending from the upper portion of the interventricular septum into the left ventricular outflow tract (panel C), with a $30 \mathrm{~mm} \mathrm{Hg}$ gradient by Dop- pler evaluation. An ECG at the time showed 2-3 mm horizontal ST segment depressions in leads I, aVL, and V4-V6. ECG gated single photon emission computed tomography (using ${ }^{99 \mathrm{~m}} \mathrm{Tc}$-tetrofosmin) revealed low perfusion at the lateral and inferior regions of the left ventricle, indicating myocardial ischaemia. Corticotropin treatment was stopped. Three months later, the patient was asymptomatic. An echocardiogram (panel D) showed the tumours had reduced in size, and there was a concomitant improvement in the depressed ST segment of the ECG.

SATOSHI HIRAISHI

NAOMI IWANAMI

NATSUKO OGAWA

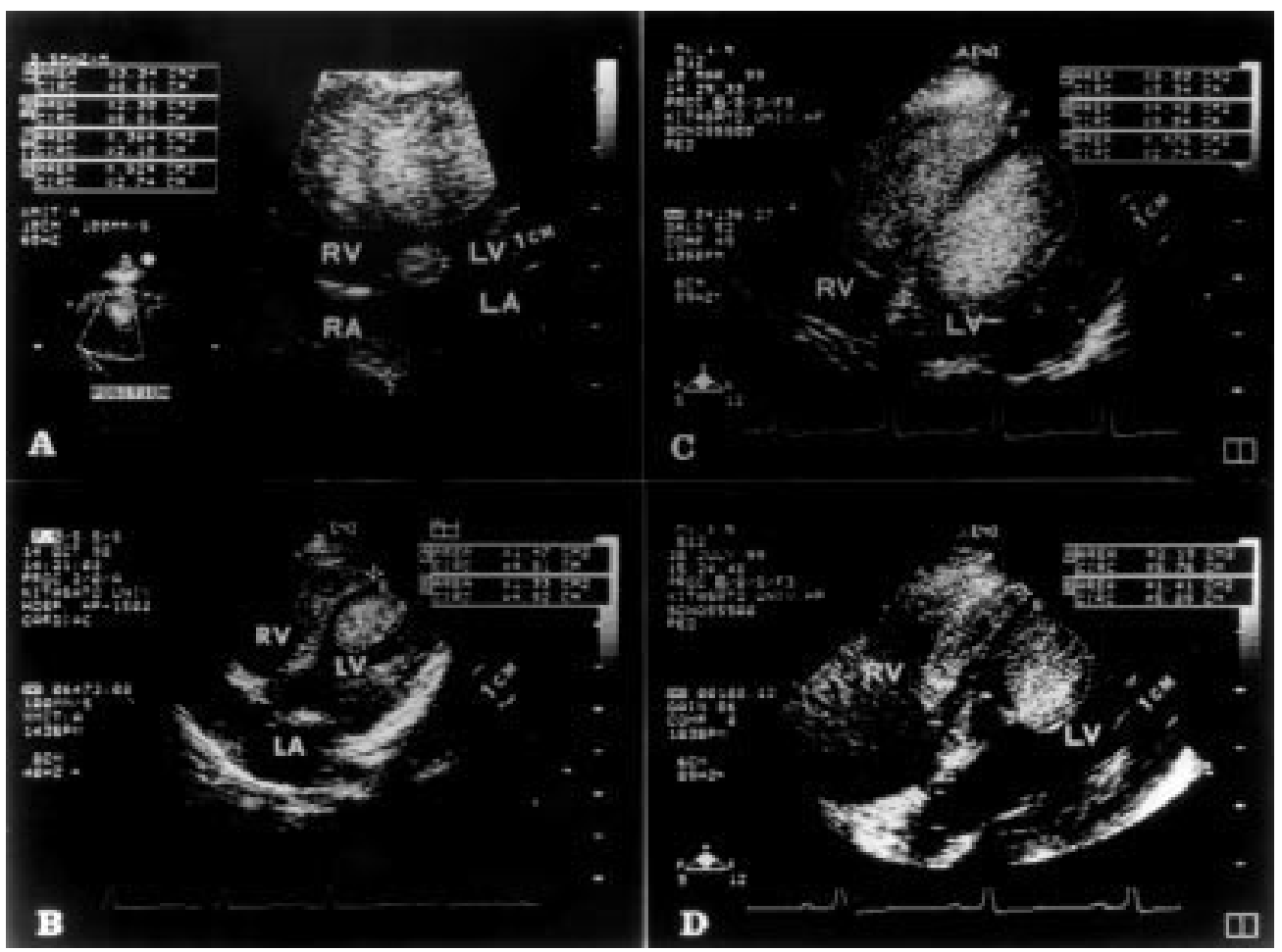

